\title{
THE EFFECTS OF THE DEFICIENCY OF CHROMOSOME V(5B) OF TRITICUM AESTIVUM ON THE MEIOSIS OF SYNTHETIC AMPHIPLOIDS
}

\author{
RALPH RILEY and VICTOR CHAPMAN \\ Plant Breeding Institute, Cambridge
}

Received 3.v. $6_{3}$

\section{INTRODUCTION}

THE chromosomes of the hexaploid wheat of commerce, Triticum astivum $(2 n=6 x=42)$, form 2 I bivalents at meiosis and the occurrence of disomic inheritance demonstrates that every chromosome pairs only with its single homologous partner. However, Riley and Chapman (1958) showed that when chromosome $V\left({ }_{5} \mathrm{~B}\right)$ was absent, from nullisomics or from nullisomic-haploids, there was non-homologous pairing and multivalents were formed. Subsequently it was demonstrated that the non-homologous pairing resulted in recombination between homoologous chromosomes, that is between genetically equivalent chromosomes of the three component genomes of T. astivum (Riley and Kempanna, 1963 ). Clearly a genetic activity of chromosome $\mathrm{V}\left({ }_{5} \mathrm{~B}\right)$ is responsible for the suppression of the meiotic affinity of homoologues. No other chromosomes of $T$. astivum performs a similar function (Riley, Chapman and Kimber, 1960), and the activity is restricted to the long arm of chromosome $\mathrm{V}\left({ }_{5} \mathrm{~B}\right)$ (Riley, ig6o).

There are several diploid species in the genera Filops and Secale -close relatives of Triticum-with attributes, such as disease resistance or winter-hardiness, which it would be useful to transfer to T. astivum. However, in hybrids between $T$. astivum and these diploids there is little or no meiotic pairing and recombination between the chromosomes of the two parents. Consequently there is a barrier to the transfer of genes of the diploids to the chromosomes of wheat. It was reasoned by Riley and Chapman (1958) that, since the activity of chromosome $\mathrm{V}\left({ }_{5} \mathrm{~B}\right)$ was responsible for the absence of meiotic pairing between homoologous chromosomes of the different genomes of wheat, the same activity might also prevent pairing and recombination between the chromosomes of wheat and those of other species, in appropriate hybrids. The validity of this reasoning was demonstrated by the occurrence of pairing between the chromosomes of the two parents of certain hybrids when chromosome $\mathrm{V}\left({ }_{5} \mathrm{~B}\right)$ was deficient, and by the absence of such pairing when it was present (Riley, Chapman and Kimber, 1959). A barrier to the transfer of foreign genes to wheat chromosomes, by meiotic recombination, can therefore be surmounted by the removal of chromosome $\mathrm{V}\left({ }_{5} \mathrm{~B}\right)$ and the genetic system, restricting the specificity of pairing, which it carries. 
Hybrids between $T$. astivum and diploid species of Egilops and Secale are sterile, due to the irregularities of chromosomes pairing at meiosis, whether chromosome $\mathrm{V}\left({ }_{5} \mathrm{~B}\right)$ is present or not. Consequently it is necessary to derive synthetic allopolyploids from chromosome $\mathrm{V}\left({ }_{5} \mathrm{~B}\right)$-deficient hybrids in order to exploit the intergenomic, or heterogenetic (Waddington, I950), meiotic affinities developed by such genotypes. These synthetic allopolyploids might be expected to be fertile and yet, by analogy with the relationship between nullisomic-V-haploid and nullisomic-V plants, continue to show homœologous pairing between the chromosomes of the three wheat genomes and those of the diploid parent. The purpose of the present paper is to describe the meiotic behaviour and possible value in practical wheatbreeding of such $\mathrm{V}\left({ }_{5} \mathrm{~B}\right)$-deficient synthetic allopolyploids, using as examples derivatives of the cross, $T$. astivum $\times$ Egilops longissima. This further exploration of the outcome of the deficiency for chromosome $\mathrm{V}\left({ }_{5} \mathrm{~B}\right)$ also adds to the understanding of the mechanism by which meiotic pairing specificity is maintained in wheat.

\section{MATERIALS AND METHODS}

The parental forms used in this work were:-AEgilops longissima Schwein. et Musch. $(2 n=14)$ and Triticum estivum L. emend. Thell. ssp. vulgare variety Holdfast, monosomic $V(5 B)(2 n-1=4 I)$.

When these two forms were used in the cross, $T$. estivum monosomic $\mathrm{V}\left({ }_{5} \mathrm{~B}\right)$ $\times A$. longissima, hybrids with 28 or 27 chromosomes were produced depending upon whether or not the monosomic chromosome $\mathrm{V}\left({ }_{5} \mathrm{~B}\right)$ had been transmitted through the embryo sac.

Synthetic polyploids were produced from these hybrids by treating them with colchicine using the capping technique described by Bell (1950). This resulted in the occurrence in the hybrid plants of sectors in which the chromosome number had been doubled. Seeds were set where such sectors occurred in inflorescences, and from the growth of these seeds the first amphiploid generation was produced. The amphiploid plants, of which the meiosis is described in the present paper, were all grown from seeds produced in the doubled sectors of hybrid plants. Consequently one amphiploid meiosis had preceded that described here.

Meiotic examinations were made on permanent squashes of anthers stained by the Feulgen procedure, with the stain intensified by the use of propionic orcein. The data dealing with the occurrence of chiasmata have been presented as the mean frequencies per cell and as the mean frequencies per paired chromosome. In calculating the latter the number of chiasmata in every cell of a sample was divided by the number of chromosomes involved in chiasmate associations in that cell, that is in bivalents, trivalents or higher associations. Plant means were then computed on the basis of these scores.

\section{RESULTS}

(i) $F_{1}$ hybrids

Meiosis has been described previously in the 28-chromosome euploid hybrids, and 27-chromosome $\mathrm{V}\left({ }_{5} \mathrm{~B}\right)$-deficient hybrids, of $T$. astivum $\times A$. longissima (Riley, Chapman and Kimber, 1959). Consequently it is probably sufficient in the present context merely to draw attention to the marked differences in the amount of chromosome pairing at first metaphase of meiosis in the two types of hybrid 
(table I). When chromosome $\mathrm{V}\left(5^{\mathrm{B}}\right)$ was present the majority of chromosomes remained as univalents (plate I, fig. I). There were some bivalents, although never more than five per cell, with a modal frequency of two. Very occasionally there were trivalents.

It is impossible to assess with certainty whether any of this meiotic pairing, in the presence of chromosome $\mathrm{V}\left({ }_{5} \mathrm{~B}\right)$, took place between the chromosomes of the two parental species. Nevertheless, since there was slightly more pairing in these hybrids than in $2 \mathrm{I}$-chromosome haploids of $T$. estivum (Riley, 1960), wheat and Egilops chromosomes may have paired occasionally. However, this happened, if at all, with such a low frequency that it would be hard to extract recombinants between chromosomes of the two species in a practical breeding project.

TABLE $I$

Mean pairing at first metaphase of meiosis of $F_{1}$ hybrids of the cross $\mathrm{T}$. æstivum $\times$ A. longissima, with and without chromosome $V\left({ }_{5} B\right)$. (50 cells per plant)

\begin{tabular}{|c|c|c|c|c|c|c|c|}
\hline $\begin{array}{c}\text { Chrom. } \\
\text { V(5B) }\end{array}$ & $\begin{array}{c}\text { Chrom. } \\
\text { no. }\end{array}$ & \multicolumn{4}{|c|}{ Mean pairing } & $\begin{array}{c}\text { Chiasmata } \\
\text { per cell }\end{array}$ & $\begin{array}{l}\text { Chiasmata per } \\
\text { paired chrom. }\end{array}$ \\
\hline & univ. & biv. & triv. & quad. & & \\
\hline Present & 28 & 24.20 & $1 \cdot 78$ & 0.08 & $\ldots$ & $1 \cdot 94 \pm 0.25$ & $0.3926 \pm 0.0321$ \\
Absent & 27 & 6.36 & $6 \cdot 18$ & $1 \cdot 30$ & $1 \cdot 04$ & $14 \cdot 18 \pm 0.35$ & $0 \cdot 7058 \pm 0.0135$ \\
\hline
\end{tabular}

In the 27-chromosorne hybrids deficient for chromosome $\mathrm{V}\left({ }_{5} \mathrm{~B}\right)$ there was considerable meiotic pairing - a mean of only $6 \cdot 36$ chromosomes per cell remaining as univalents (plate I, fig. 2). Trivalents and quadrivalents were common, there being as many as five multivalents in some cells. There were no associations of more than four chromosomes and this, in conjunction with the rarity of quadrivalents in chromosome $\mathrm{V}\left(5^{\mathrm{B}}\right)$-deficient haploids of $\mathcal{T}$. astivum (Riley, I96o) and the evidence of homoeologous pairing in $\mathrm{V}\left({ }_{5} \mathrm{~B}\right)$ nullisomics (Riley and Kempanna, i 963 ), may be taken to indicate that the quadrivalents in these hybrids each involved a set of three homœologous wheat chromosomes and the corresponding chromosome of $A$. longissima. Although the quadrivalents provided the only conclusive evidence of pairing between wheat and Egilops chromosomes, it may be assumed that chromosomes of both species were also involved together in bivalents and trivalents. Consequently the probability of recombination between wheat and Egilops chromosomes must be greatly enhanced when chromosome $\mathrm{V}(5 \mathrm{~B})$ is absent.

However, for the purposes of practical breeding it would be difficult to exploit hybrids of this type because of their meiotically determined male sterility, and low female fertility. An apparently easier alternative might be to attempt to employ their synthetic polyploid derivatives, to avoid the sterility of the initial hybrid. This 
possibility was suggested by Riley, Chapman and Kimber (I959) but for it to be feasible there must still be, in the chromosome $\mathrm{V}\left(5^{\mathrm{B}}\right)$ deficient amphiploid, homœologous meiotic pairing between the chromosomes of the parental species. The $T$. astivum $\times A$. longissima amphiploids provide an opportunity for the examination of the question.

\section{(ii) Amphiploids}

The first generation amphiploid derivatives of 28-chromosome hybrids varied in chromosome number (table 2), presumably due to the functioning of some gametes with numerically unbalanced chromosome complements produced on the amphiploid sectors of the parents.

TABLE 2

The distribution of individuals with various chromosome numbers in the amphiploid derivatives of colchicined $F_{1}$ hybrids of the cross $\mathrm{T}$. æstivum $\times$ A. longissima, with and without chromosome $V\left(5^{B}\right)$.

\begin{tabular}{|c|c|c|c|c|c|c|c|c|c|c|c|}
\hline \multirow{2}{*}{\multicolumn{2}{|c|}{$\begin{array}{l}\text { Chrom. } \\
V\left(5^{B}\right)\end{array}$}} & & \multirow{2}{*}{$\begin{array}{c}\mathrm{F}_{1} \\
\text { chrom. } \\
\text { no. }\end{array}$} & \multicolumn{7}{|c|}{$\begin{array}{l}\text { No. of amphiploid plants with various } \\
\text { chromosome numbers }\end{array}$} & \multirow{2}{*}{ Total } \\
\hline & & & & 50 & $5^{I}$ & $5^{2}$ & 53 & 54 & 55 & 56 & \\
\hline Presen & & . & 28 & I & 4 & 7 & 9 & I I & Io & 7 & 49 \\
\hline Absent & . & . & 27 & 2 & 0 & 2 & 5 & 4 & 0 & 0 & 13 \\
\hline
\end{tabular}

Riley and Chapman (I957) showed that in $T$. cestivum $\times$ A. longissima amphiploids, there was some pairing failure at meiosis and that the exclusion of unpaired chromosomes from functional gametes led to the occurrence of aneuploid individuals, even in the first amphiploid generation.

Indeed the extent of this pairing failure may be seen from the present results (table 3), in which two 56-chromosome euploids, plants I/I and I/2, were scored at meiosis. Both had considerable amounts of bivalent failure at first metaphase. One cell of plant I/I had eight univalents and 24 bivalents, and one of plant I/2 had I 2 univalents and 22 bivalents. Only I 7 per cent. of the cells scored in plant $\mathrm{I} / 2$ and 60 per cent. in plant $\mathrm{I} / \mathrm{I}$, had full chromosome pairing with 28 bivalents (plate I, fig. 3), so that the production of a range of aneuploid individuals in the progenies of euploid sectors is not unexpected. The remaining three derivatives of 28-chromosome hybrids that were scored at meiosis, were aneuploids which presumably originated from meiotic irregularities of this type.

Plant I/3, with 54 chromosomes, was monosomic for two chromosomes and at its maximum meiotic pairing had 26 bivalents and two univalents. Plant $\mathrm{I} / 4$, with 54 chromosomes, was nullisomic for one chromosome pair and at its maximum pairing had 27 bivalents. 
Plant I/IO, with 53 chromosomes, was nullisomic for one pair and monosomic for another, so that the maximum pairing at meiosis was one univalent and 26 bivalents.

All these plants presumably carried chromosome $\mathrm{V}\left(5^{\mathrm{B}}\right)$ since they were derived from hybrids in which it was present. Moreover the pronounced contrast, between the general regularity of their meiosis and the irregularity of meiosis in amphiploid individuals derived from $\mathrm{V}\left({ }_{5} \mathrm{~B}\right)$-deficient hybrids indicates that none of the aneuploidy resulted in the complete absence of this critical chromosome (table 3 ). Despite this, however, there were low frequencies of trivalents and quadrivalents. Multivalents occurred in only between 6 per cent. and i 3 per cent. of cells, and there was never more than one multivalent per cell. Presumably these multivalents arose from the association together of chromosomes of $T$. astivum and $A$. longissima, because multivalents do not normally occur in either parent. Since A. longissima is closely related to $A$. speltoides (Riley, Kimber and Chapman, I96I), the species which probably contributed the B genome of T. astivum (Riley, Unrau and Chapman, 1958), it is not surprising to find evidence of some meiotic affinity between its chromosome and those of $T$. estivum, even in the presence of chromosome $\mathrm{V}\left({ }_{5} \mathrm{~B}\right)$.

However, the amount of heterogenetic pairing displayed in these amphiploids was insufficient to permit readily the introduction of segments of $A$. longissima chromosomes into wheat chromosomes. For this purpose it is necessary to turn to the amphiploid derivatives of hybrids deficient for chromosome $\mathrm{V}\left({ }_{5} \mathrm{~B}\right)$.

These amphiploids also differed in chromosome number but amongst the plants scored at meiosis were three with 54 chromosomes (table 3 ). These must be presumed to have had all the chromosomes of the two parent species, other than the $\mathrm{V}\left({ }_{5} \mathrm{~B}\right)$ pair of $T$. astivum. In the case of plant $6 / 2$ this assessment of the chromosomal constitution could be accepted unequivocally since one cell was observed with 27 bivalents. Every cell of the other two 54-chromosome plants was so complex that an accurate diagnosis of the chromosome status of the plants was impossible. Four of the other plants analysed meiotically had 53 chromosomes and were apparently nullisomic for chromosome $\mathrm{V}\left({ }_{5} \mathrm{~B}\right)$ and monosomic for another chromosome. The extreme irregularity of the meiosis of plant $6 / 5$, which had 52 chromosomes, precluded an accurate diagnosis of its constitution, so that in addition to being nullisomic for chromosome $\mathrm{V}\left({ }_{5} \mathrm{~B}\right)$ it might have been either nullisomic for a second pair or doubly monosomic.

Despite the differences in chromosome numbers, meiosis in all these amphiploids, deficient for chromosome $\mathrm{V}\left({ }_{5} \mathrm{~B}\right)$, was essentially similar. Multivalents were common and on occasions large (plate I, fig. 4). In all the 240 cells of these plants analysed in detail, to obtain the means listed in table 3 , only three had no multivalents whatsoever. Two of these cells, one with 27 bivalents and the other with four univalents and 25 bivalents, were from plant $6 / 2$ and the other, with five 


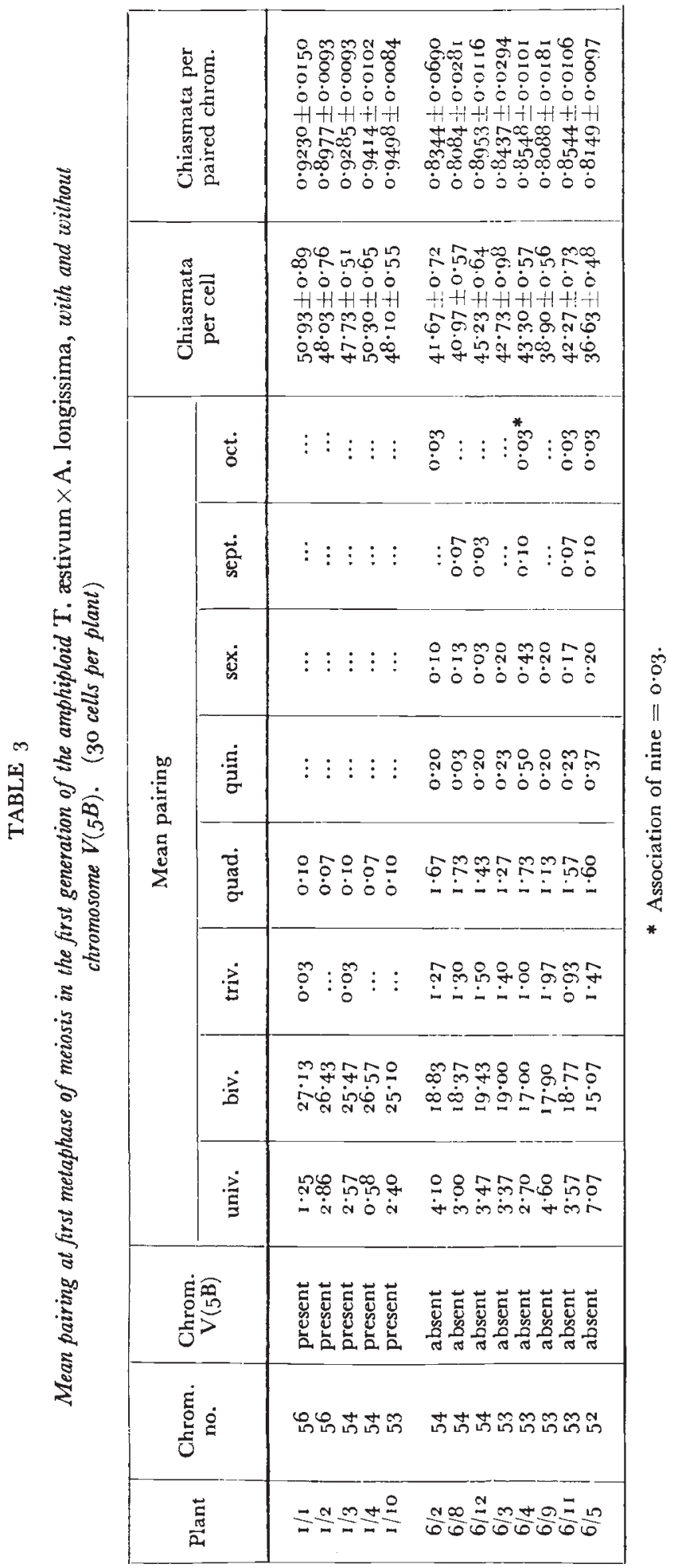


univalents and 24 bivalents, was from plant $6 / \mathrm{II}$. In plants $6 / 4$ and $6 /$ I I the maximum number of multivalents in any cells was seven, while in all the other plants six was the maximum number. Octavalents, septivalents and sexivalents were not uncommon (plate II, fig. 3), while trivalents or quadrivalents occurred in almost every cell (plate I, fig. 4, and plate II, figs. I and 2). The complexity of the meiosis in these plants may be judged from one cell of plant $6 / 12$ which had 13 bivalents, two trivalents, three quadrivalents and two quinquevalents, or from a cell of plant $6 / 4$ in which there were one univalent, I 4 bivalents, one quadrivalent, one quinquevalent, one septivalent and one octavalent. Clearly the pronounced multivalent pairing resulted from the

TABLE 4

Fertility of primary and secondary florets in two bagged inflorescences of amphiploids derived from the cross T. æstivum $\times$ A. longissima

\begin{tabular}{|c|c|c|c|c|c|}
\hline Plant & $\begin{array}{c}\text { Chromosome } \\
\text { no. }\end{array}$ & $\begin{array}{c}\text { Chromosome } \\
\mathrm{V}\left(5^{\mathrm{B}}\right)\end{array}$ & Florets & Seeds & $\begin{array}{l}\text { Proportion } \\
\text { fertile }\end{array}$ \\
\hline $\begin{array}{l}1 / 1 \\
1 / 2 \\
1 / 3 \\
1 / 4 \\
1 / 10\end{array}$ & $\begin{array}{l}56 \\
56 \\
54 \\
54 \\
53\end{array}$ & $\begin{array}{l}\text { present } \\
\text { present } \\
\text { present } \\
\text { present } \\
\text { present }\end{array}$ & $\begin{array}{l}28 \\
60 \\
56 \\
64 \\
64\end{array}$ & $\begin{array}{r}14 \\
16 \\
13 \\
8 \\
10\end{array}$ & $\begin{array}{l}0.50 \\
0.27 \\
0.23 \\
0.13 \\
0.16\end{array}$ \\
\hline $\begin{array}{l}6 / 2 \\
6 / 8 \\
6 / 12 \\
6 / 3 \\
6 / 4 \\
6 / 9 \\
6 / 11 \\
6 / 5\end{array}$ & $\begin{array}{l}54 \\
54 \\
54 \\
53 \\
53 \\
53 \\
53 \\
52\end{array}$ & $\begin{array}{l}\text { absent } \\
\text { absent } \\
\text { absent } \\
\text { absent } \\
\text { absent } \\
\text { absent } \\
\text { absent } \\
\text { absent }\end{array}$ & $\begin{array}{l}72 \\
92 \\
68 \\
84 \\
76 \\
74 \\
80 \\
80\end{array}$ & $\begin{array}{l}29 \\
27 \\
39 \\
14 \\
11 \\
25 \\
29 \\
43\end{array}$ & $\begin{array}{l}0.41 \\
0.29 \\
0.57 \\
0.17 \\
0.14 \\
0.34 \\
0.36 \\
0.54\end{array}$ \\
\hline
\end{tabular}

intergenome affinities revealed in the absence of chromosome $\mathrm{V}\left({ }_{5} \mathrm{~B}\right)$. By analogy with the results of Riley and Kempanna (1963), on $\mathrm{V}\left({ }_{5} \mathrm{~B}\right)$ deficient forms of $\mathcal{T}$. astivum, the present multivalent formation arose from the pairing of homœologues. However, to achieve the octavalents attained in the maximum associations recorded in these amphiploids, all six homœologues of $T$. astivum in addition to the corresponding chromosome pair from $A$. longissima must have been involved (plate II, fig. 3). Associations of seven may be presumed to have included all these chromosomes except one. These large associations provide the only certain evidence of pairing between wheat and Egilops chromosomes but in view of their occurrence it seems reasonable to assume that chromosomes of the two parents were also involved together in smaller multivalents and even in bivalents. There may consequently be a considerable amount of recombination between wheat and REilops chromosomes in these amphiploids.

A striking aspect of the meiotic behaviour of these chromosome $\mathrm{V}\left({ }_{5} \mathrm{~B}\right)$-deficient amphiploids was the high frequency of univalents. This was accompanied not only by lower mean chiasma frequencies 
but also by lower frequencies of chiasmata per paired chromosome (table 3). Thus the alteration of meiotic pairing specificity which results from the absence of chromosome $\mathrm{V}\left({ }_{5} \mathrm{~B}\right)$ was associated with a reduction in the extent to which synaptic attractions were realised.

The seed fertility of the amphiploids deficient for chromosome $\mathrm{V}\left({ }_{5} \mathrm{~B}\right)$ was not greatly different from that of the amphiploids in which it was present (table 4). Certainly their fertility was sufficient to permit their ready use in breeding work.

\section{DISCUSSION}

(i) The utilisation of the deficiency of chromosome $V(5 B)$ in wheat breeding

The impact can now be considered of the present results on the problems of practical plant breeding involved in the introduction of useful alien genetic variation into wheat. The major obstacle to this in the past has been the absence of recombination between wheat chromosomes and those of many species of Secale, Egilops and Agropyron, in appropriate hybrids and amphiploids. The present work amply demonstrates that chromosome $\mathrm{V}\left({ }_{5} \mathrm{~B}\right)$-deficient amphiploid genotypes provide reasonably fertile material in which recombination between wheat and alien chromosomes occurs quite commonly. Thus the two principal barriers to the exploitation of alien variation can be overcome; the meitoic barrier by the absence of chromosome $\mathrm{V}\left({ }_{5} \mathrm{~B}\right)$, and the sterility barrier by the use of amphiploid genotypes.

The present results demonstrate, in principle, the usefulness of amphiploids in which meiotic pairing specificity is relaxed, though the evidence is confined to the chromosome $\mathrm{V}\left({ }_{5} \mathrm{~B}\right)$-deficient amphiploid $T$. astivum $\times A$. longissima. However, it is probably fair to generalise from this work, and to assert that if the pairing specificity differs in hybrids with and without chromosome $\mathrm{V}\left({ }_{5} \mathrm{~B}\right)$, as it does in the $T$. astivum $\times A$. longissima hybrids, then their amphiploid derivatives will be similarly distinctive in meiotic behaviour. Moreover, if in the hybrid deficient for chromosome $\mathrm{V}\left({ }_{5} \mathrm{~B}\right)$ there was evidence of heterogenetic meiotic pairing between chromosomes of different species, then it is likely that similar pairing will persist in the amphiploid. Published results show that hybrids of $T$. astivum with Secale cereale (Riley, Chapman and Kimber, I959), S. montanum (Kempanna and Riley, I 962), Egilops caudata (Muramatsu, 1959) and with $A$. cylindrica (Riley, 1960) have pairing patterns in which recombination between chromosomes of the two parents could be expected in the amphiploids deficient for chromosome $\mathrm{V}\left({ }_{5} \mathrm{~B}\right)$. Unpublished results from work at Cambridge indicate the likelihood of similar behaviours in the equivalent amphiploids of $T$. astivum with Egilops turcomanica, $A$. ovata, A. triuncialis and $A$. umbellulata.

From this it is clear that a range of hitherto inaccessible genetic variation is made available to wheat breeding by knowledge of the relaxation of meiotic pairing specificity which follows from the absence 
of chromosome $\mathrm{V}\left({ }_{5} \mathrm{~B}\right)$. The precise method used to transfer variation to wheat will no doubt depend upon the complexity of the inheritance of the character concerned. However, certainly for the transfer of simply inherited characters, the $\mathrm{V}\left(5^{\mathrm{B}}\right)$-deficient amphiploid will probably be used in backcrossing programmes, with $T$. astivum as the recurrent parent. Often it may be worthwhile to allow several amphiploid generations to elapse, in order to increase the probability of the occurrence of appropriate heterogenetic recombination, before backcrossing is initiated.

Another potentially useful variation of the backcrossing technique may be employed to avoid the restoration of the restricted, entirely homologous, pairing specificity which follows the re-introduction of chromosome $\mathrm{V}\left({ }_{5} \mathrm{~B}\right)$. In this procedure the amphiploid might be crossed, not with a normal euploid form of $T$. estivum, but with a form deficient for chromosome $\mathrm{V}\left({ }_{5} \mathrm{~B}\right)$. The derivatives of this cross would be deficient for chromosome $\mathrm{V}\left({ }_{5} \mathrm{~B}\right)$ and would carry only the haploid set of alien chromosomes. Consequently the probability of pairing and recombination between wheat and alien chromosomes might well be increased by an absence of homologous competition in the alien set. The recurrent parent in this programme could continue to be a form of $T$. estivum lacking chromosome $\mathrm{V}\left({ }_{5} \mathrm{~B}\right)$, this critical chromosome being restored only in the final backcross generation. One generation of selfing would then be needed to obtain chromosome $\mathrm{V}\left({ }_{5} \mathrm{~B}\right)$ in the disomic condition.

While emphasis has been placed on the value of amphiploids lacking chromosome $\mathrm{V}\left({ }_{5} \mathrm{~B}\right)$, for the introduction of alien variation, it may be that the initial hybrids, from which the amphiploids were derived, should not be entirely neglected. Their very low fertility makes the use of these hybrids difficult, but occasionally seeds will set if the hybrids are pollinated on a large scale with the pollen of normal plants of $T$. astivum. There is thus some small opportunity of exploiting the much greater amounts of allosyndetic meiotic pairing and recombination that occurs at this chromosome level, in which all pairing is homœologous.

\section{(ii) The mechanism of synapsis}

The absence of chromosome $\mathrm{V}\left({ }_{5} \mathrm{~B}\right)$ from the $T$. astivum $\times A$. longissima amphiploids results in a relaxation of the specificity of meiotic chromosome pairing. By analogy with the results of Riley and Kempanna (1963), on forms of $T$. astivum lacking the chromosome, it can be assumed that the abnormal pairing resulted from the conjugation of homœologues in addition to homologues.

The altered patterns of pairing, at first metaphase, which follow the absence of the chromosome, could result from changes in the processes which initiate synapsis or from alterations in the frequencies or distributions of chiasmata. Kimber (196I) has shown from prophase studies that, in euploid forms of $T$. estivum, synapsis is restricted to pairs of chromosomes and that there are no higher associations. In addition 
Riley (I960) has reported that there were no marked differences, in the numbers or distributions of chiasmata, between plants of $T$. estivum nullisomic for chromosome $\mathrm{V}\left({ }_{5} \mathrm{~B}\right)$ and euploid individuals. Consequently it seems that the differences in metaphase pairing result from alterations in the specificity of synapsis, at prophase.

Further confirmation of this is provided by the behaviour of the two types of amphiploid studied in the present work. The numbers of chiasmata per cell and per paired chromosome were clearly lower when chromosome $\mathrm{V}\left({ }_{5} \mathrm{~B}\right)$ was absent. Consequently the occurrence of multivalents was certainly not due to a higher chiasma frequency. In addition, the distribution of chiasmata at first metaphase, was not detectably different in the two types of plant. Therefore multivalent formation was not related to alterations in the positions of the chiasmata. It may be concluded, therefore, that the development of multivalents by homœologous pairing results from changed specificities during synapsis and that chromosome $\mathrm{V}\left({ }_{5} \mathrm{~B}\right)$ carries a gene system which alters the threshold of structural equivalence needed for the initiation of synapsis (Riley and Kempanna, I963).

The lower mean frequencies of chiasmata per cell and per paired chromosome, as well as the generally higher mean numbers of univalents per cell, in the amphiploids deficient for chromosome $\mathrm{V}\left({ }_{5} \mathrm{~B}\right)$, can be viewed in two ways. Either chromosome $\mathrm{V}\left({ }_{5} \mathrm{~B}\right)$ produces an effect on the frequency of chiasmata independently of its effect on pairing specificity, or the two effects are causally related.

Although the simplest explanation appears to be that the two effects are related there is no obvious way of separating the alternatives until such time as a simple genetic variant, giving relaxed pairing specificity, is discovered. Such material would be necessary to determine whether chromosome $\mathrm{V}\left({ }_{5} \mathrm{~B}\right)$ exercises a genetic regulation of chiasma frequency quite separately from its control of pairing specificity.

A relationship becween the effects could arise from the greater competition for partners that occurs amongst the chromosomes potentially capable of pairing when synaptic specificity is relaxed. The synaptic affinity of a chromosome for six homœologues might be insufficient to guarantee homœologous pairing while diminishing the probability of pairing between homologues. As a result of this synaptic competition there may thus be a conflict between the relaxation of synaptic specificity and the degree to which synapsis is realised.

This apparent association of reduced chiasma frequency with multivalent formation resembles the relationship reported to exist between the chiasma frequencies of certain autotetraploids and those of their diploid relatives. Evidence was assembled by Upcott ( I 939) and by Morrison and Rajhathy (I96o $a$ and $b$ ) which showed that the frequencies of chiasmata in polyploids were lower than the expectations computed from the frequencies in their diploid parents. Upcott ascribed the low frequencies to delays in pairing, resulting from the increased sizes of the nuclei of polyploids, and dismissed the possibility 

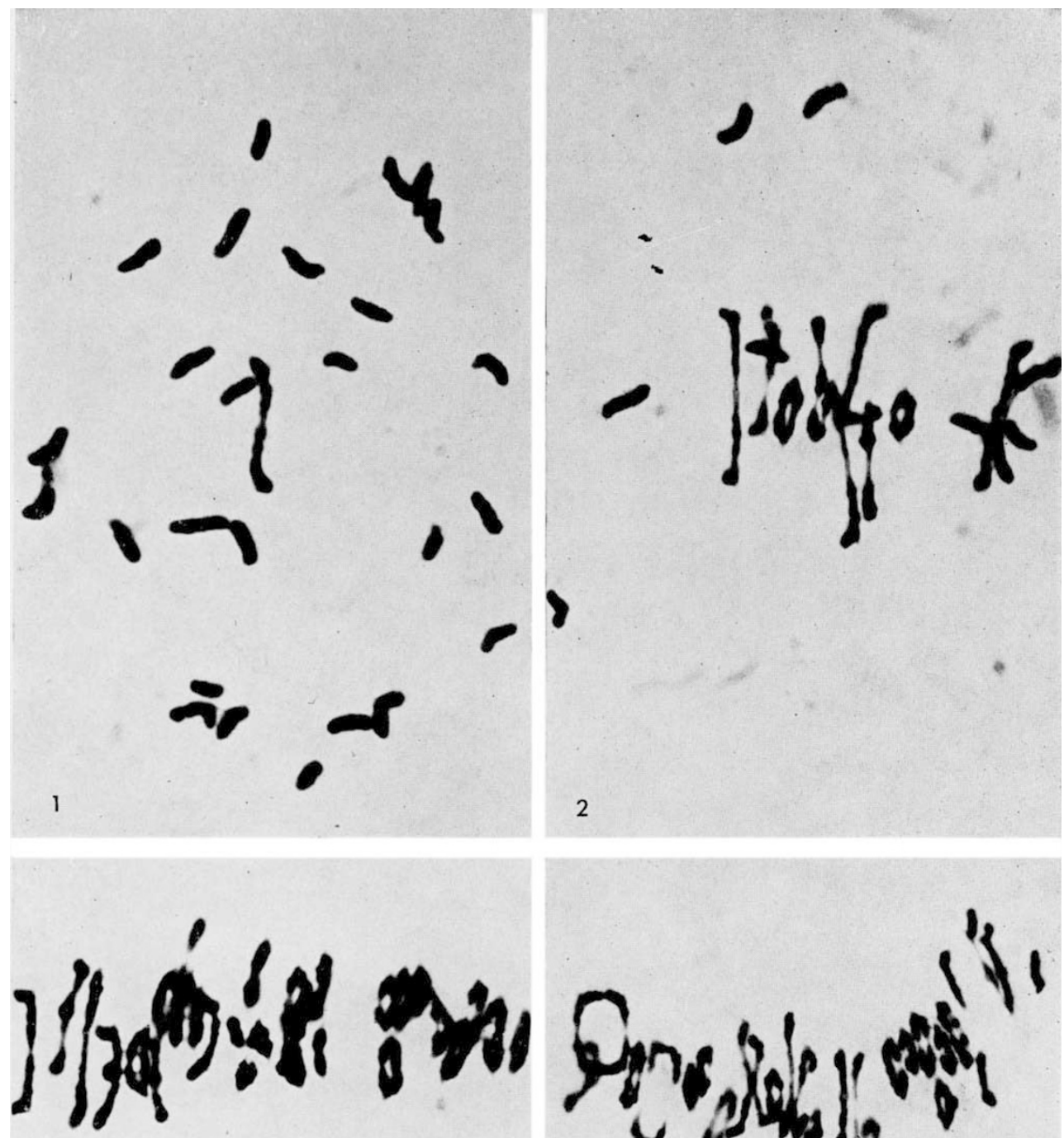

3

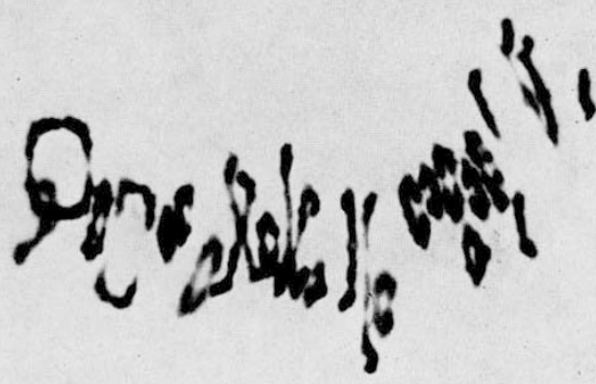

4

First metaphase of meiosis in pollen mother cells of $\mathrm{F}_{1}$ hybrids of the cross $T$, estivum monosomic $\mathrm{V}(5 \mathrm{~B})(2 n-\mathrm{I}=4 \mathrm{I}) \times$ A. longissima $(2 n=14)$ and its amphiploid derivatives.

FIG. 1.-A 28-chromosome $F_{1}$ hybrid, with chromosome $V\left({ }_{5} B\right)$ present; one bivalent and 26 univalents.

FIG. 2.-A 27-chromosome $F_{1}$ hybrid, deficient for chromosome $\mathrm{V}\left({ }_{5} \mathrm{~B}\right)$, two quadrivalents, six bivalents, seven univalents.

FiG. 3.-A 56 -chromosome amphiploid, plant $1 / \mathrm{r}$, with chromosome $\mathrm{V}\left(5^{\mathrm{B}}\right)$ present and disomic ; 28 bivalents.

FIG. 4.-A 54-chromosome amphiploid, plant $6 / 2$, deficient for chromosome $\mathrm{V}(5 \mathrm{~B})$; two quadrivalents, one trivalent, 2 I bivalents and one univalent. 


\section{Plate II}

First metaphase in pollen mother cells of chromosome $\mathrm{V}\left({ }_{5} \mathrm{~B}\right)$-deficient amphiploids of the cross $T$. astivum monosomic $\mathrm{V}\left({ }_{5} \mathrm{~B}\right)(2 n-\mathrm{I}=4 \mathrm{I}) \times A$. longissima $(2 n=\mathrm{I} 4)$.

Fig. I.-A 54-chromosome amphiploid, plant $6 / 12$; two quadrivalents, three trivalents, 17 bivalents, three univalents.

Fig. 2.-A 53 -chromosome amphiploid, plant $6 / 3$; one quinquevalent, two quadrivalents, one trivalent, 17 bivalents (two overlying), three univalents.

Fig. 3.-A 53-chromosome amphiploid, plant $6 / 4$, to show an octavalent-the remainder of the cell out of focus. 

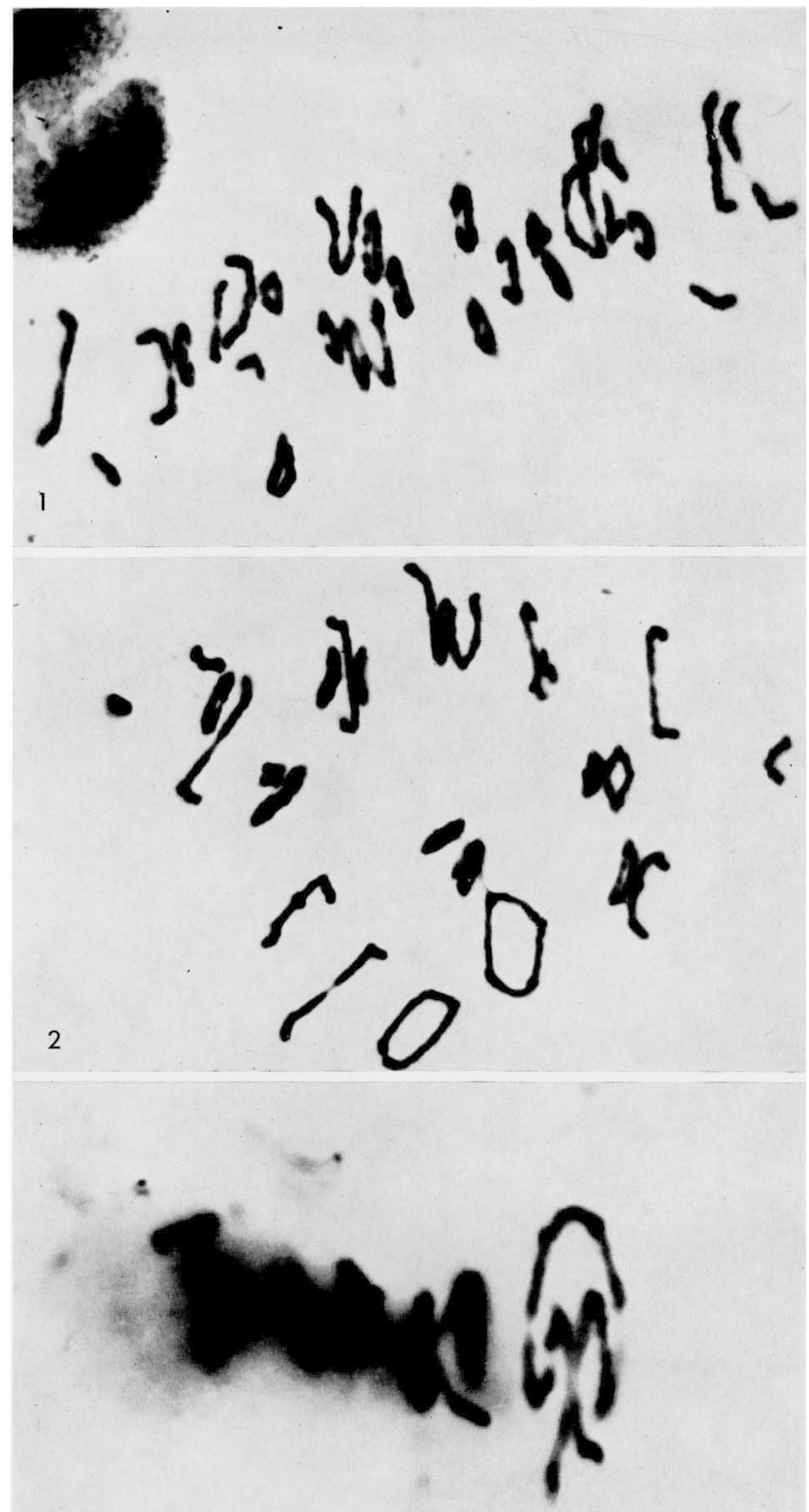
that they resulted from changes of partner between homologous chromosomes since similarly low frequencies also occurred in allopolyploids.

It is clear, however, that a lower frequency of chiasmata per chromosome is not a constant feature of autotetraploidy since Callan ( I949) and John and Henderson (I 962) have scored samples of tetraploid cells, in several insect species, in which there were more than twice the number of chiasmata found in their diploid counterparts. The greater nuclear volumes which these tetraploid cells must be presumed to have had, relative to their diploid equivalents, did not delay pairing to such an extent as to impede chiasma formation. Consequently the reduced frequencies in the material described by Upcott and by Morrison and Rajhathy may also have resulted not from delayed pairing but from synaptic competition like that postulated to occur in the multivalent-forming amphiploids of the cross $T$. astivum $\times$ A. longissima.

The differences between the two sorts of autotetraploid behaviour may perhaps be dependent upon differences in the extent, or number, of the regions at which pairing can be initiated. Species like $T$. estivum and its relatives, and the cereal species described by Morrison and Rajhathy (I96oa), apparently have rather restricted, and essentially distal, contact regions so that synaptic competition is likely under multivalent-forming conditions. By contrast in the insect species described by John and Henderson most of the extra chiasmata formed in autopolyploid cells were in the long chromosomes, in which there may be several contact regions. The combined operation of these regions could well overcome synaptic competition, and the changes of partner in the multivalents remove interference, to give frequencies of chiasmata per chromosome in excess of the levels in diploids.

\section{SUMMARY}

At meiosis in the hybrid Triticum estivum $(2 n=6 x=42) \times$ Egilops longissima $(2 n=14)$ there was little or no pairing between the chromosomes of the two species in the presence of chromosome $\mathrm{V}\left(5^{\mathrm{B}}\right)$ of $T$. estivum. However, such pairing occurred freely when chromosome $\mathrm{V}\left(5^{\mathrm{B}}\right)$ was absent. Similar heterogenetic pairing can also be demonstrated to take place, in the absence of the wheat chromosome, in many other interspecific hybrids.

All these initial hybrids are largely sterile; consequently it may be necessary to use their amphiploid derivatives to exploit heterogenetic recombination in attempts to introduce alien genetic variation into the wheat crop. In the present work, therefore, meiosis has been examined in amphiploids derived from the cross $T$. astivum $\times A$. longissima. Meiosis was quite regular in the presence of chromosome $\mathrm{V}\left(5_{\mathrm{B}}\right)$, apart from some bivalent failure and the formation of rare trivalents or quadrivalents. In the absence of chromosome $\mathrm{V}\left({ }_{5} \mathrm{~B}\right)$, however, large multivalents were frequent and heterogenetic pairing 
between the chromosomes of the two species could de demonstrated. Amphiploids deficient for chromosome $\mathrm{V}\left({ }_{5} \mathrm{~B}\right)$ were as fertile as those in which the chromosome was present. It was concluded, therefore, that amphiploid material, deficient for chromosome $\mathrm{V}\left({ }_{5} \mathrm{~B}\right)$, could be of value in permitting the introduction into wheat chromosomes of agriculturally beneficial genes from related species.

The amphiploid material demonstrated that the homœologous pairing that takes place at meiosis in $T$. astivum, in the absence of chromosome $\mathrm{V}\left(5_{5} \mathrm{~B}\right)$, does not result from increases in the frequency or changes in the distribution of chiasmata. Indeed there were lower chiasma frequencies in the multivalent-forming conditions, and it is suggested that these lower frequencies may result from synaptic competition.

Acknowledgments - It is a pleasure to acknowledge the technical assistance of Mr T. E. Miller and Mr H. A. Torrens.

\section{REFERENCES}

BELL, G. D. H. 1950. Investigations in the Triticinæ. I. Colchicine techniques for chromosome doubling in interspecific and intergeneric hybridisation $\mathcal{J}$. agric. Sci., 40, 9-18.

CallaN, H. G. 1949. Chiasma interference in diploid, tetraploid and interchange spermatocytes of the earwig, Forficula auricularia. 7. Genet., 49, 209-2 I 3 .

JOHN, B., AND HENDERSON, S. A. I962. Asynapsis and polyploidy in Schistocerca paranensis. Chromosoma (Berl.), 13, II I-147.

KEMPANNA, C., AND RILEY, R. I962. Relationships between the genetic effects of deficiencies for chromosomes III and $\mathrm{V}$ on meiotic pairing in Triticum estivum. Nature, Lond., r95, 1270-1273.

KIMBER, G. 1962. The effect of chromosome 5B at prophase. Wheat Inf. Service I4, 3-5. MORRISON, J. W., AND RAJHATHY, T. Ig6oa. Chromosome behaviour in autotetraploid cereals and grasses. Chromosoma (Berl.), II, 297-309.

MORRISON, J. W., AND RAJHATHY, T. 196ob. Frequency of quadrivalents in autotetraploid plants. Nature, Lond., I87, 528-530.

MURAmatsU, T. 1959. Homology of chromosomes of Agilops caudata with common wheat. Wheat Inf. Service, 9-10, 32-33.

RILEY, R. 1960. The diploidisation of polyploid wheat. Heredity, 15, 407-429.

RILEY, R., AND CHAPMAN, V. 1957. The comparison of wheat-rye and wheatAgilops amphidiploids. 7. agric. Sci., 49, 246-250.

RILEY, R., AND CHAPMAN, v. I958. Genetic control of the cytologically diploid behaviour of hexaploid wheat. Nature, Lond., r82, 713-7I5.

RILEY, R., CHAPMAN, V., AND KIMBER, G. I959. Genetic control of chromosome pairing in intergeneric hybrids with wheat. Nature, Lond., I83, 1244-1246.

RILEY, R., ChaPMAN, V., AND KIMBER, G. I960. Positions of the gene determining the diploid-like meiotic behaviour of wheat. Nature, Lond., r86, 259-26o.

RILEY, R., AND KEMPANNA, c. 1963. The homceologous nature of the non-homologous meiotic pairing in Triticum estivum deficient for chromosome $\mathrm{V}\left({ }_{5} \mathrm{~B}\right)$. Heredity, I8, 287-306.

RILEY, R., KIMBER, G., AND CHAPMAN, V. I $96 \mathrm{I}$. The origin of the genetic control of the diploid-like meiotic behaviour of polyploid wheat. 7. Hered., 52, 22-26.

RILEY, R., UNRAU, J., AND CHAPMAN, v. 1958. Evidence on the origin of the B genome of wheat. 7. Hered., 49, $91-99$.

upcotт, M. 1939. The nature of tetraploidy in Primula kewensis. 7. Genet., 39, 79-1 00. waddington, C. H. 1950. An Introduction to Modern Genetics. George Allen \& Unwin, Ltd., London. 